\title{
PEDAGOGIA HISTÓRICO-CRÍTICA EM FRANCISCO BELTRÃO-PR (1990-2014): CAMINHOS E DESCAMINHOS
}

\author{
HISTORICAL-CRITICAL PEDAGOGY IN FRANCISCO BELTRÃO-PR(1990-2014): UPS \\ AND DOWNS
}

\author{
PEDAGOGÍA HISTÓRICO-CRÍTICA EN FRANCISCO BELTRÃO-PR (1990-2014): \\ CAMINOS Y DESCAMINOS
}

\author{
Tassia Lima de Camargo ${ }^{1}$, André Paulo Castanha ${ }^{2}$
}

\section{RESUMO:}

O presente texto é resultado de investigações sobre o processo de institucionalização e implantação da Pedagogia Histórico-Crítica (PHC) em Francisco Beltrão-PR, entre 1990 e 2014. Para a realização da pesquisa, utilizamos fontes documentais, bibliográficas e entrevistas. Discorremos sobre os fundamentos teóricos e metodológicos da PHC, em seguida realizamos uma análise das políticas educacionais do Paraná. Por fim, discutimos sobre a PHC na rede municipal de Francisco Beltrão, percebendo os distanciamentos e aproximações com essa pedagogia de caráter contra hegemônico. Por ser uma teoria revolucionária, percebemos que temos muito a avançar, para que a PHC passe de um objetivo proclamado nos documentos e se torne um objetivo real, condição para a qual precisamos agir a partir de condições concretas, com a clareza de que a história se constrói mediada por ações humanas conscientes e coletivas, que dão a plena possibilidade de realizar uma educação voltada à emancipação da classe trabalhadora.

PALAVRAS-CHAVE: Educação e Emancipação. Prática Pedagógica. Educação no Paraná.

\section{ABSTRACT:}

The essay is the result of investigations about the process of institutionalization and deployment of HistoricalCritical Pedagogy in Francisco Beltrão-PR, between 1990 and 2014. For the realization of essay we used documental, bibliographic, and interviews sources. Talking about the theoretical and methodological foundations of the Historical-Critical Pedagogy, next the analysis of education policies of Paraná. Finally, the Historical-Critical Pedagogy of municipal network in Francisco Beltrão, understanding of estrangements and approaches with this Pedagogy of counter-hegemonic character. By being the revolutionary theory, we understand to advance for the Historical-Critical Pedagogy pass of objective proclaimed in documents and come back the real objective, to this end we need the actions onwards precise conditions had direct that the history is built thru of conscience and collectives human actions, being possible to realize the education oriented to emancipation of working class.

Key-words: Education and emancipation. Pedagogical practice. Education of Paraná.

\footnotetext{
${ }^{1}$ Mestra em Educação e Pedagoga - Universidade Estadual do Oeste do Paraná (UNIOESTE) - Campus de Francisco Beltrão, PR. Brasil - Professora efetiva da Rede Municipal de Ensino de Francisco Beltrão, PR. Brasil. E-mail: tassiadecamargo@hotmail.com

2 Doutor em Educação - Universidae Federal de São Carlos (UFSCar) - São Carlos, SP. Brasil - Pós-doutor em Filosofia e História da Educação - Universidade Estradual de Campinas (UNICAMP) - Campinas, SP, Brasil Professor do Colegiado de Pedagogia e do Mestrado em Educação - Universidade Estadual do Oeste do Paraná ( UNIOESTE) - Campus de Francisco Beltrão, PR. Brasil E-mail: andrecastanha66@gmail.com Submetido em: 17/11/2016 - Aceito em: 18/06/2017
}

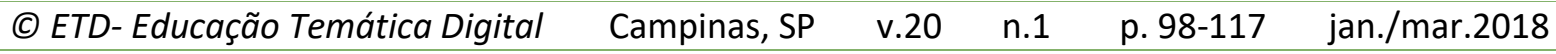




\section{RESUMEN:}

El presente texto es resultado de investigaciones sobre el proceso de institucionalización e implantación de la Pedagogía Histórico-Crítica (PHC) en Francisco Beltrão-PR entre 1990 y 2014. Para la realización de la investigación utilizamos fuentes documentales, bibliográficas y de entrevistas. Discurrimos sobre los fundamentos teóricos y metodológicos de la $\mathrm{PHC}$, en seguida realizamos una análisis de las políticas educacionales del Paraná. Por fin discutimos sobre la PHC en la red municipal de Francisco Beltrão, percibiendo los distanciamientos y aproximaciones con esa pedagogía de carácter contra hegemónico. Por ser una teoría revolucionaria, percibimos que tenemos mucho lo que avanzar para que la PHC pase de un objetivo proclamado en los documentos y se vuelva un objetivo real, para eso necesitamos actuar a partir de condiciones concretas tenendo claro que la história se construye mediada por acciones humanas conscientes y colectivas siendo plenamente posible realizar una otra educación volcada para la emancipación de la clase trabajadora.

PALABRAS CLAVE: Educación y Emancipación.Práctica Pedagógica. Educación en el Paraná.

\section{INTRODUÇÃO}

Como indicado por Rosa e Castanha (2015), a Pedagogia Histórico-Crítica, se comparada à História da Educação Brasileira, é bastante recente. Todavia, em sua breve existência de menos de quarenta anos, não só marcou presença e se tornou conhecida, como passou a figurar como referência constante, tanto "na história da educação, como nos Projetos Políticos e Pedagógicos (PPPs) das escolas e até mesmo nas propostas pedagógicas das Secretarias de Estado da Educação e também de Secretarias Municipais de Educação". Concordando ou não com ela, adotando ou não na prática pedagógica, "ela está presente nas discussões travadas no interior dos estabelecimentos educacionais e faz parte das referências dos educadores, especialmente no Paraná" (2015, p. 1).

A partir dessa constatação, o presente artigo tem como objetivo investigar em que medida a concepção da Pedagogia Histórico-Critica, de base marxista, é colocada em prática nas instituições educativas da rede municipal de Francisco Beltrão-PR, de modo a promover a apreensão de códigos científicos que favoreçam uma nova interpretação do mundo e uma prática social transformada. Justifica-se tal investigação o fato de que, por orientações das Secretarias Estaduais e Municipais de Educação, os Projetos Político-Pedagógicos das escolas aparecem fundamentados por essa teoria. Para tanto, utilizamo-nos de meios documentais e bibliográficos, além de entrevistas com professores, gestores e com o próprio Dermeval Saviani, fundador da teoria.

Para dar conta do objetivo, dividimos o texto em três tópicos. Primeiramente, discorremos sobre as raízes teóricas e metodológicas da PHC, evidenciando que essa pedagogia é revolucionária, crítica e almeja, portanto, a emancipação da classe trabalhadora, por meio do acesso ao saber científico, da união entre instrução e trabalho e da organização política e cultural das massas. Em seguida, tratamos da Pedagogia HistóricoCritica no Paraná, mediante a análise das Políticas Educacionais Paranaenses de 1990 a 2014. Por fim, discutimos a Pedagogia Histórico-Crítica na Rede Municipal de Francisco

$\begin{array}{llllll}\text { (C) ETD-Educação Temática Digital Campinas, SP } & \text { v.20 } & \text { n.1 } & \text { p. } 98-117 & \text { jan./mar.2018 }\end{array}$


Beltrão, estabelecendo relações com as políticas estaduais e buscando compreender como elas refletem na organização da educação municipal; analisamos as propostas pedagógicas curriculares, o plano municipal de educação do município, do período de 1990 a 2014, e evidenciamos as contradições e possibilidades de objetivação dessa pedagogia socialista, no contexto da pesquisa.

\section{PEDAGOGIA HISTÓRICO-CRÍTICA: FUNDAMENTOS TEÓRICOS E METODOLÓGICOS}

Dermeval Saviani, embasado nos princípios marxistas, formulou uma pedagogia brasileira de caráter contra hegemônico, crítica e revolucionária. Essa pedagogia tem como princípio formativo promover a igualdade e a liberdade entre os homens, por meio do acesso ao conhecimento científico. Marx, Lênin e Gramsci refletiram sobre as relações entre sociedade e educação, mas não chegaram a formular uma teoria propriamente pedagógica. Saviani, a partir dos pressupostos marxistas, avançou significativamente nesse processo, ao formular um método pedagógico que explicita uma concepção de sociedade, de homem e de educação que visa à transformação social. Nessa perspectiva, o homem é um sujeito concreto que atua sobre a sua realidade e pode transformá-la; é fruto das relações histórico-sociais estabelecidas com seus semelhantes; e é formado pelo processo de educação e pelo trabalho. No dizer de Saviani:

\footnotetext{
A essência humana não é então, dada ao homem; não é uma dádiva natural; não é algo que precede a existência do homem. Ao contrário, a essência humana é produzida pelos próprios homens. O que o homem é, o é pelo trabalho. A essência do homem é um feito humano. É um trabalho que se desenvolve, se aprofunda e se complexifica ao longo do tempo: é um processo histórico (SAVIANI, 2013, p. 104).
}

Dessa forma, a criança deve ser educada para trabalhar, uma vez que o trabalho, enquanto valor de uso, deve ser encarado como uma atividade vital ao ser humano. Ou seja, educar para o trabalho, na visão marxista, não é o mesmo que educar para o trabalho na visão capitalista, na qual é apenas ajustar o sujeito ao sistema vigente, que não promove sua autonomia e liberdade.

Para tanto, para que ocorra a conscientização das massas, Marx defende um ensino voltado à emancipação do proletariado, com uma formação integral e politécnica (união da formação intelectual, manual e física). Ou seja, a união entre instrução e trabalho, para que o educando tenha o domínio intelectual das bases produtivas e não se torne um corpo dócil e adestrado que realiza atividades mecânicas e abstratas, sem a consciência do que faz. Pensando na formação desse sujeito histórico, Marx e Engels apresentaram sua proposta de ensino: 
Por educação entendemos três coisas: 1) Educação intelectual. 2) Educação corporal, tal como a que se consegue com os exercícios de ginástica e militares. 3) Educação tecnológica, que recolhe os princípios gerais e de caráter científico de todo o processo de produção e, ao mesmo tempo, inicia as crianças e os adolescentes no manejo de ferramentas elementares dos diversos ramos industriais. À divisão das crianças e adolescentes em três categorias, de nove a dezoito anos, deve corresponder um curso graduado e progressivo para sua educação intelectual, corporal e politécnica. Os gastos com tais escolas politécnicas serão parcialmente cobertos com a venda de seus próprios produtos. Esta combinação de trabalho produtivo pago com a educação intelectual, os exercícios corporais e a formação politécnica elevará a classe operária acima dos níveis das classes burguesa e aristocrática (2004, p. 68-69).

Para atingir seus objetivos, a Pedagogia Histórico-Crítica segue o rigor científico do método de Marx, em que o conhecimento parte da realidade empírica, dela se busca extrair as suas contradições e determinações, ou seja, parte do senso comum, de um todo caótico para chegar ao concreto pensado. Assim, o processo de ensino/aprendizagem bem conduzido faz com que o indivíduo consiga elaborar suas próprias sínteses no campo do pensamento, o que significa passar de uma visão desarticulada, fragmentada e incoerente, para uma visão unitária explícita e original da realidade. Esse método "constitui uma orientação segura para o processo de descoberta de novos conhecimentos (o método científico) como para o processo de transmissão-assimilação de conhecimentos (o método de ensino)" (SAVIANI, 2008, p. 74).

O método preconizado por Saviani está vinculado diretamente à prática social do sujeito, fazendo com que ele incorpore, nas suas ações cotidianas, elementos culturais e científicos, para poder transformar a sua prática social, tendo sempre em vista a emancipação da classe trabalhadora. Segundo ele:

\footnotetext{
Tais métodos se situarão para além dos métodos tradicionais e novos, superando por incorporação as contribuições de uns e de outros. Portanto, serão métodos que estimularão a atividade e iniciativa dos alunos sem abrir mão, porém, da iniciativa do professor; favorecerão o diálogo dos alunos entre si e com o professor, mas sem deixar de valorizar o diálogo com a cultura acumulada historicamente; levarão em conta os interesses dos alunos, os ritmos de aprendizagem e o desenvolvimento psicológico, mas sem perder de vista a sistematização lógica dos conhecimentos, sua ordenação e gradação para efeitos do processo de transmissão-assimilação dos conteúdos cognitivos [...]. Os métodos que preconizo mantêm continuamente presente a vinculação entre educação e sociedade. Enquanto no primeiro caso professor e alunos são sempre considerados em termos individuais, no segundo caso, professor e alunos são tomados como agentes sociais (SAVIANI, 2008, p. 69).
}

Por ter essa relação íntima com a sociedade e ser de natureza crítica, a Pedagogia Histórico-Crítica evidencia elementos históricos e sociais, algo que estava ausente na Pedagogia Tradicional e Nova, que concebem a educação de forma autônoma, com relação à sociedade. No entendimento de Saviani,

$\begin{array}{llllll}\text { (C) ETD-Educação Temática Digital } & \text { Campinas, SP } & \text { v.20 } & \text { n.1 } & \text { p. 98-117 } & \text { jan./mar.2018 }\end{array}$


[...] nessas pedagogias está ausente a perspectiva historicizadora. Falta-lhes a consciência dos condicionantes histórico-sociais da educação. São, pois, ingênuas e não críticas já que é próprio da consciência crítica saber-se condicionada, determinada objetivamente, materialmente, ao passo que a consciência ingênua é aquela que não se sabe condicionada, mas, ao contrário, acredita-se superior aos fatos, imaginando-se mesmo capaz de determiná-los e alterá-los por si mesma. Eis porque, tanto a pedagogia tradicional como a pedagogia nova entendiam a escola como "redentora da humanidade". Acreditavam que era possível modificar a sociedade através da educação (2008 p.63).

Por estar historicamente condicionada, podemos afirmar que a educação e a escola não se fecham em seus limites, portanto, não são estáticas, estão sempre sofrendo influências da realidade que, no caso, é sustentada por princípios capitalistas. Nessa perspectiva

A escola é determinada socialmente; a sociedade em que vivemos, fundada no modo de produção capitalista é dividida em classes com interesses opostos; portanto, a escola sofre a determinação do conflito de interesses que caracteriza a sociedade. Considerando-se que a classe dominante não tem interesse na transformação histórica da escola (ela está empenhada na preservação do seu domínio, portanto acionará mecanismos de adaptação que evitem a transformação) segue-se que uma teoria crítica (que não seja reprodutivista) só poderá ser formulada do ponto de vista dos interesses dominados (SAVIANI, 2008, p. 30).

Por essa razão, pensar numa educação que tenha em vista a superação do atual modelo socioeconômico, implica em investir na formação política dos docentes, para que almejem/lutem por mudanças estruturais na sociedade, ou seja, alimentem a utopia de um mundo melhor. A atuação no campo pedagógico, portanto, demanda que se tenha em mente qual educação se quer defender, uma vez que ela pode colaborar para legitimar os valores burgueses ou estar a serviço dos valores da classe dominada, constituindo-se numa das frentes para a superação da sociedade excludente ${ }^{3}$. Assim, para lutar em favor da libertação das massas, precisamos ter conhecimento da teoria e clareza das metodologias que sustentam esses objetivos emancipatórios. Essa é a função da pedagogia revolucionária, dar sustentação à luta dos trabalhadores, para que não caiam nas armadilhas capitalistas, de modo que seus interesses não se confundam aos da burguesia.

\footnotetext{
${ }^{3}$ Autores como Favaro (2015), Lazarini (2010) e Tumolo $(2005,2011)$ têm criticado a leitura da centralidade do princípio educativo do trabalho formulada por Saviani e sua relação com a educação escolar. Sustentam que a PHC precisa ser redimensionada em seus aspectos político-estratégicos e, até mesmo, educacionais, para que possa dar conta dos desafios atuais, sob o risco de se esvaziar de seus objetivos socialistas e acabar contribuindo para a manutenção da sociedade capitalista.
}

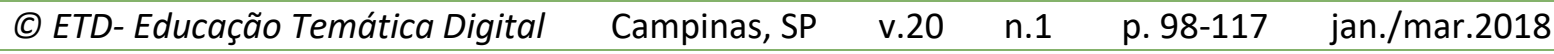




\section{PEDAGOGIA HISTÓRICO-CRÍTICA NO PARANÁ: PRINCÍPIOS E CONTRADIÇÕES}

A década de 1980 foi caracterizada pelo fim da ditadura civil-militar. Nesse contexto, foram pensadas políticas que beneficiavam a classe trabalhadora de forma mais efetiva. Nas eleições de 1982, como estratégia para conquistar a vitória, o PMDB levantou a bandeira da igualdade e da democracia, apropriou-se das lutas que vinham sendo travadas pelos educadores que clamavam por uma educação voltada aos interesses das camadas populares, com princípios de liberdade e de emancipação humana, cuja base era a socialização dos conhecimentos científicos elaborados socialmente. Assim, o governo, como forma de ganhar força e representatividade junto à categoria dos docentes, apropriou-se desse movimento em favor de uma educação democrática como se fosse um avanço de sua política.

No Paraná, o governo peemedebista de José Richa (1983-1986) priorizou uma educação democrática, que permitiu a um número maior da população o acesso à escola, e incentivou formas de ações participativas da comunidade. Desse modo, podemos afirmar que o grande avanço de sua gestão foi a democracia e a descentralização administrativa no âmbito escolar, com a implantação dos núcleos regionais e a escolha dos gestores via eleições e não mais por indicação.

Neste contexto de participação popular na escola, ganharam destaques os sindicatos e grêmios estudantis, como forma de fortalecer a representatividade coletiva. Também houve modificações nos regimentos escolares, na tentativa de romper com práticas pedagógicas e posturas autoritárias. Conforme afirmou Tonidandel, "A SEED propõe a descentralização do poder, ampliando as possibilidades de pais, professores, alunos e da comunidade participar das decisões da escola" (2014, p.137).

A administração de José Richa também investiu na melhoria das condições de trabalho para os educadores, realizou concurso público, garantiu avanços salariais, propiciou oportunidades de formação continuada e possibilitou inovações didáticas.

Os pressupostos da política educacional do Governo de Álvaro Dias (1987-1990) continuaram evidenciando os princípios de redemocratização escolar, com o objetivo de promover a justiça, a liberdade e a igualdade de oportunidades para toda população, na busca de construir um "Paraná Moderno". Durante aquele período marcado pela forte organização popular em prol da garantia e conquista de direitos, os governantes não tinham outra opção que não fosse acatar as exigências sociais. Então, diante de tal conjuntura, 
Dias reiterou o discurso oposicionista de Richa. Retoma a discussão política da educação, da democratização, da descentralização da gestão e da melhoria da infraestrutura escolar, concedeu alguns benefícios trabalhistas aos trabalhadores da educação pública. Além disso, destacou a educação como fator de mudança social e teceu críticas ao "modelo ainda concentrador do saber da população e da riqueza" e procurou enfrentar os índices de analfabetismo, evasão, repetência e seletividade, com o reordenamento interno do sistema educacional, o que significou empreendimento de medidas "exequíveis" administrativa e pedagogicamente. Para tanto, deu ênfase ao aspecto de rendimento quanto da "renovação pedagógica" (TONIDANDEL, 2014, p.150) ${ }^{4}$.

A partir de discussões coletivas entre os gestores do Estado e os movimentos organizados dos educadores, buscando educação democrática e mudanças sociais, na gestão de Álvaro Dias foi elaborada e implantada a proposta do Ciclo Básico de Alfabetização e concluída a elaboração do Currículo Básico do Paraná, publicado no final de 1990. Conforme definido no documento,

O Ciclo Básico de Alfabetização constitui o início da reorganização do ensino de $1^{\circ}$ grau ao propor uma nova concepção de alfabetização. No Ciclo Básico, a alfabetização é o processo de apropriação da língua escrita o qual deve ser compreendido além do simples domínio do sistema gráfico. Essa concepção de alfabetização assume na escolarização um papel fundamental, pois ao instrumentalizar o aluno para sua inserção na cultura letrada, cria condições de operação mental capaz de apreensão de conceitos mais elaborados e complexos que vem resultando do desenvolvimento das formas sociais de produção (PARANÁ, 1990, p. 13).

O Ciclo Básico de Alfabetização teve por objetivo superar a mecanização do ensino, melhorar o índice de pessoas alfabetizadas, para diminuir as taxas de repetência e evasão escolar. Para alcançar esses fins, a estratégia foi reformular o sistema avaliativo, tornando-o mais inclusivo. Com o Ciclo Básico de alfabetização, houve "a reorganização do ensino de 10 Grau a partir do alargamento do tempo de alfabetização, isto é, reunir a 1a e 2a séries em um "continuum" de 2 anos, sem reprovar o aluno" (TONIDANDEL, 2014, p.152).

Frente a essas concepções de sujeito, de educação e de sociedade provocadas com a implantação do Ciclo Básico, foi indispensável pensar sobre novas proposições curriculares para a Escola Pública do Paraná. "O departamento de Ensino de 1o grau desencadeou em conjunto com as equipes dos Núcleos Regionais, vários encontros e cursos, visando o processo de análise e reconstrução dos conteúdos das áreas do conhecimento" (PARANÁ, 1990, p. 13). É importante ressaltar que o Currículo Básico do Paraná não surgiu do acaso,

\footnotetext{
${ }^{4}$ No entanto, apesar de ter um plano político pautado na democratização do ensino, as ações do governo de Álvaro Dias foram contraditórias, pois, no dia 30 de agosto de 1988, durante manifestação dos professores, foram praticados atos de violência contra os educadores, justamente na época de construção e implantação do Currículo Básico. Esse fato nos leva a crer que o governo não estava preocupado em promover uma educação de qualidade voltada à criticidade e emancipação humana.
}

(C) ETD-Educação Temática Digital Campinas, SP $\quad$ v.20 $\quad$ n.1 $\quad$ p. 98-117 jan./mar.2018


mas passou por longo processo de discussão coletiva, amadurecimento teórico por parte de um grupo de educadores que lutavam contra a ditadura e buscavam uma forma de superar as pedagogias existentes, agindo em favor de uma educação crítica, histórica e transformadora, conforme as manifestações do contexto sociopolítico da época.

A década de 1990 representou uma grande descontinuidade com relação à política educacional contra hegemônica que vinha sendo discutida no Estado do Paraná durante a década de 1980. Na década de 1990, as políticas neoliberais ganharam força, tanto em âmbito nacional como estadual. Esse fato afetou a organização das instituições que estavam submetidas aos interesses do Fundo Monetário Internacional-FMI, do Banco Mundial e outras agências financiadoras do governo, atrelando aos interesses do capital a educação.

A gestão de Roberto Requião de Melo e Silva (1991-1994) assumiu o compromisso de dar continuidade ao processo de consolidação do Currículo Básico e ao processo de democratização do ensino, garantindo qualidade e universalidade, todavia, na prática, não foi isso que aconteceu. No seu governo, as escolas passaram a ter autonomia para criar um Projeto Político-Pedagógico sob a orientação do documento "Paraná Construindo a Escola Cidadã", publicado em 1992 (BACZINSKI, 2011, p. 59). Esse documento estava baseado na descentralização das ações, respeitando as diferentes visões pedagógicas das instituições, e era pautado por princípios de valorização da pluralidade, deixando os professores livres para escolherem suas concepções e metodologias pedagógicas. Entretanto, essa liberdade das escolas foi construída de forma vertical, sem a participação popular, estando mais a serviço de um projeto neoliberal, do que para a transformação social.

Para cumprir seus compromissos de garantia de qualidade e universalização da educação básica, o governo buscou recursos junto ao Banco Interamericano de desenvolvimento-BID e de outros segmentos da sociedade. Roberto Requião ampliou o Ciclo Básico de alfabetização para três anos, o que demandou maior investimento na estrutura física, formação de professores e materiais didáticos, para o que realizou um empréstimo junto ao Banco Mundial, "Dando início no Paraná, aos acordos com instituições multilaterais de financiamentos, como BIRD e o BID que introduziram reformas neoliberais mediante a perspectiva de ações que privilegiassem a inclusão social" (BACZINSKI, 2011, p. 59). É importante ressaltar que a política educacional paranaense, nos anos 1990, estava unida com os princípios educacionais defendidos por Fernando Henrique Cardoso, de modo que o estado adequou as escolas aos moldes do capital, relegando a segundo plano a formação humana e científica, supervalorizando a formação técnica necessária ao mercado de trabalho.

A educação adequada aos interesses do capital teve maior relevância, nas duas gestões do governo Jaime Lerner, que correspondem ao período de 1995 a 2002. Um dos

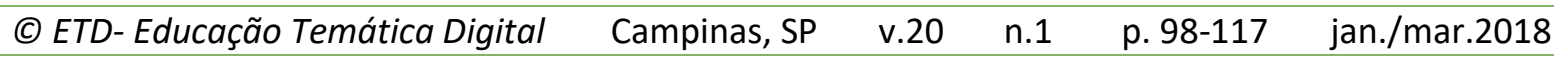


objetivos centrais defendido por esse governo foi o de construir uma escola de excelência, para que os paranaenses atingissem a cidadania. Assim, propôs formas compartilhadas de gestão, como uma maneira de dividir suas responsabilidades com a comunidade. Todavia, essa busca de parcerias com diversos segmentos da sociedade configurou as práticas mercantilistas e minimalistas de seu governo, que ficou marcado por constantes convênios firmados com o Banco Mundial, com objetivo de modernizar o ensino tornando-o mais eficaz.

O Projeto Qualidade do Ensino Público-PQE também fez parte do Plano de Ação de Jaime Lerner, visando a aperfeiçoar a eficácia do Ensino Fundamental. Para realizá-lo, firmou parceria com o BIRD e investiu em materiais pedagógicos como forma de possibilitar às crianças de baixa renda um espaço apropriado para aprender com sucesso, aumentando os índices de aprovação e combatendo a evasão. A preocupação com a qualidade nesse nível de ensino ocorreu, pois, segundo a lógica do governo Lerner, de modo que a educação básica era responsável pela formação da mão de obra primária para atender as necessidades do mercado. No entender de Piton:

O governo do Paraná atribuía grande importância ao BIRD. Isso é próprio da lógica neoliberal que coloca a centralidade na educação básica. O ensino fundamental, financiado pelo BIRD, é a parte (primeira) da educação básica que vai preparar a força de trabalho para a execução de tarefas simples (ao ensino médio cabe a preparação de força de trabalho as tarefas mais complexas) para o aumento da produtividade e a garantia de ampliação do capital (2004, p. 77)

Objetivando a inovação da educação paranaense, investiu também na capacitação dos profissionais. No entanto, as atividades de formação continuada ofertadas pela SEED corresponderam aos princípios neoliberais, de modo que os cursos realizados na Universidade do Professor em Faxinal do Céu $^{5}$, em parceria com instituições privadas, tinham conteúdos motivacionais centrados na valorização do indivíduo, proporcionando aos professores flexibilidade e criatividade frente aos novos paradigmas educacionais. As capacitações estavam fundamentadas por princípios empresarias pelos quais o aluno passou a ser visto como "cliente", configurando, assim, uma organização mercadológica nas escolas e fortalecendo as bases do capital.

\footnotetext{
${ }^{5}$ Segundo Magalhães, Jaime Lerner, como governador do Estado, pelo Partido da Frente Liberal (PFL) e Paulo Renato de Souza, como Ministro da Educação, pelo Partido da Social Democracia Brasileiro (PSDB), "Esses dois senhores foram aqueles que chancelaram um convênio com o Banco Mundial para construírem um centro de formação designado por Universidade do Professor, em Faxinal do Céu no Paraná, a fim de objetivar o Projeto Qualidade do Ensino Público/PR (PQE). Essa 'Universidade' atuou na formação continuada dos professores da rede pública do Paraná e sua base pedagógica era a intuição e a motivação particular para a resolução de problemas pedagógicos da escola, fundamentada numa lógica empresarial (2012, p. 33).
}

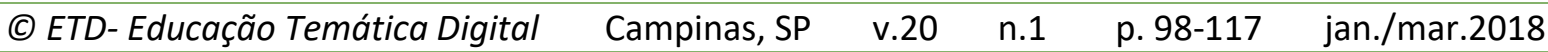


Na campanha eleitoral de 2002, para governo do Estado do Paraná, Roberto Requião (PMDB) foi enfático nas críticas feitas ao projeto neoliberal defendido por seu antecessor e se propôs a superá-lo. No mesmo período, Luiz Inácio Lula da Silva (PT) venceu as eleições presidenciais e também se comprometeu em alterar aquele projeto societário existente, contrapondo-se à lógica do "Estado Mínimo" defendida por FHC. Sobre esse projeto, Frigotto afirmou:

\begin{abstract}
A conjuntura desta década se diferencia da década de 1990 em diversos aspectos, tais como: retomada, ainda que de forma problemática, da agenda do desenvolvimento; alteração substantiva da política externa e da postura perante as privatizações; recuperação, mesmo que relativa, do Estado na sua face social; diminuição do desemprego aberto, mesmo que tanto os dados quanto o conceito de emprego possam ser questionados; aumento real do salário mínimo (ainda que permaneça mínimo); relação distinta com os movimentos sociais, não mais demonizados nem tomados como caso de polícia; e ampliação intensa de políticas e programas direcionados à grande massa não organizada que vivia abaixo da linha da pobreza ou num nível elementar de sobrevivência e consumo (2011, p. 240).
\end{abstract}

Diante da ascensão do PT ao poder em âmbito nacional, Roberto Requião (PMDB/PR) também se utilizou de jargões na campanha, afirmando categoricamente que seu governo era de esquerda. A partir disso, fez todo um discurso ideológico junto aos educadores, levando a categoria a acreditar que realmente o governo estava em defesa de seus interesses, quando, na verdade, "os interesses do Estado são inconciliáveis com os da educação e do magistério. Por isso, necessitava camuflar e mistificar sua posição, confundir os docentes, cooptá-los ideologicamente e procurar evitar que se organizassem, amainando suas resistências, pressões e lutas" (ORSO e TONIDANDEL, 2014, p.137).

A partir de 2003, as políticas educacionais voltam a resgatar princípios da PHC, pois os governos nacional e estadual redimensionaram as políticas neoliberais em vigência até aquele momento. Então, no Estado do Paraná iniciaram-se as discussões sobre o Plano Estadual de Educação, e, por consequência, foram reelaborados os Projetos PolíticoPedagógicos e as Diretrizes Curriculares Estaduais. Diante dessas mudanças de concepções, também foi investido fortemente no processo Formação Continuada dos Professores com a instituição do Programa de Desenvolvimento Educacional-PDE, e os documentos e atividades que embasavam a formação tinham os pressupostos teóricos da Pedagogia Histórico-Critica, ainda que por vezes apenas no âmbito do discurso ideológico e legal.

Apesar do empenho de Requião em implantar uma pedagogia revolucionária no âmbito do discurso e no plano legal, ela não se efetivou e nem mesmo irá se efetivar, enquanto for bandeira política para a conquista do poder, quando, nem mesmo a equipe de governo conhece seus objetivos e fundamentos e os defende realmente. Por ser uma 
pedagogia contra-hegemônica, a PHC vai contra os interesses do Estado, por isso requer um comprometimento coletivo de classe.

\section{APROXIMAÇÕES E DISTANCIAMENTOS EM RELAÇÃO À PEDAGOGIA HISTÓRICO-CRÍTICA NA REDE MUNICIPAL DE EDUCAÇÃO DE FRANCISCO BELTRÃO}

Nos anos 1990, a proposta que estava presente nas escolas municipais de Francisco Beltrão era o Currículo Básico do Paraná, que incorporou o Ciclo Básico de alfabetização. Essa proposta estava alicerçada em concepções teóricas e metodológicas que se aproximavam dos princípios da PHC.

No entanto, muitas dificuldades e contradições permearam a objetivação da proposta de alfabetização, contida no Currículo Básico do Paraná, pela Rede Municipal de Educação de Francisco Beltrão. Essas dificuldades se deram tanto pelas condições materiais de trabalho, quanto pelos aspectos de formação docente, pois, por estar embasado teoricamente pelos pressupostos da Pedagogia Histórico-Crítica, que na época era ainda pouco conhecida entre os docentes, dificultou a concretização da proposta, visto que antes de colocar em prática uma tendência era/é preciso conhecê-la e ter claros seus objetivos, que implicam uma concepção de educação, de homem e de sociedade.

As dificuldades citadas persistem até hoje, passadas mais de duas décadas de oficialização do documento, mas, o Currículo Básico ainda se constitui numa das principais referências, quando tratamos sobre as discussões referentes à Pedagogia Histórico-Crítica no Paraná. Por consequência, o mesmo ocorre em nível municipal, pois se caracterizou como a primeira tentativa de implantação de uma pedagogia contra-hegemônica, em Francisco Beltrão, e se constitui numa importante fonte de pesquisa na elaboração dos PPPs atuais.

No ano de 1998, na gestão do Prefeito Guiomar de Jesus Lopes-PMDB (1997-2000), foi construída a primeira proposta pedagógica própria em esfera municipal, centrada na Pedagogia Libertadora denominada "Criança Cidadã", fundamentada em Paulo Freire. O Secretário Municipal de Educação da época, o senhor Nestor Luiz Morgan, afirmou que o município estava consolidando sua autonomia em relação ao estado, ao formular e implantar a proposta Criança Cidadã:

Então, a partir desse momento a equipe como um todo pode ouvir as escolas, levar uma proposta até as escolas, e atender um pouquinho mais aquele anseio que o pessoal tinha de ter um apoio didático-pedagógico e uma linha mais definida para atuação do corpo docente como um todo, enquanto educação do município de Francisco Beltrão (MORGAN, 2015). 
Freire dialoga com o marxismo por meio de um princípio educativo que almeja formar o homem livre de toda opressão, tomando a educação como uma ferramenta fundamental para garantir a igualdade social, fazendo com que os alunos tenham consciência de si no/do mundo.

São inegáveis as contribuições de Paulo Freire à educação brasileira, e a principal delas consiste em aproximar a escola do contexto social do educando, fazendo com que os alunos tenham consciência de sua dominação e possam agir em benefício da sua libertação e do seu grupo. Então, assim como Saviani, Paulo Freire enfatizou que a educação é um ato político, não neutro, muito menos um ato mecânico, abstrato e reprodutivista, que apenas colabora para conservação da divisão de poder entre as classes.

Ambos os estudiosos têm como ponto de partida do processo de ensino e aprendizagem a vivência cotidiana da criança. No entanto, observamos que muitos professores da rede municipal de Francisco Beltrão consideram que para trabalhar numa perspectiva crítica basta valorizar essa prática social inicial do aluno sem a devida metodologia sustentada por princípios emancipatórios. Isso acaba por não dar condições para os sujeitos se apropriarem dos conhecimentos historicamente elaborados, e, por consequência, eles não conseguem superar a sua dominação, deixando de agir para o desenvolvimento de uma nova ordem social fundada nos princípios da justiça, da igualdade e da liberdade. Cabe lembrar que o processo educativo, sem a instrumentalização, problematização, aquisição e a apropriação do saber científico, torna a aprendizagem utilitarista e relativista a serviço da solução dos problemas imediatos, não completando o ato de humanização do homem.

É fato que alguns estudiosos do marxismo tecem críticas à Pedagogia Freireana, alegando que ela tem base fenomenológica, com princípios da Escola Nova, ao apostar na livre iniciativa do educando ao aprender. Todavia, cabe aqui enfatizar a sua respeitável contribuição para nossa educação, no sentido de construir uma pedagogia emancipatória, pois, na maioria de seus aspectos, ela se aproxima e dialoga com a teoria marxista, ao contrário, por exemplo, das de base construtivista, que procuram legitimar as diferenças, agindo em favor da conservação do poder da classe burguesa. O próprio Saviani declarou, em entrevista, que, em certa medida, a Pedagogia Libertadora e a Pedagogia HistóricoCrítica se aproximam, no sentido de que ambas objetivam a emancipação da classe trabalhadora, porém se diferenciam no sentido de que Freire não coloca a escola como a principal instituição a serviço da socialização do saber historicamente produzido pela a humanidade. Conforme Saviani (apud CAMARGO; CASTANHA, 2016): 
Eu diria que há uma certa relação em termos do objetivo mais amplo, porque tanto a Pedagogia Histórico-Crítica como a pedagogia libertadora, a pedagogia de Paulo Freire, estão empenhadas em desenvolver um ensino relevante para a classe trabalhadora. Ambas buscam desenvolver um tipo de educação para as camadas populares, que possibilite à classe trabalhadora um poder emancipatório, potencializando sua capacidade de luta, sua capacidade de se libertar da dominação vigente na sociedade. No entanto, elas se diferenciam na medida em que a pedagogia de Paulo Freire se centra mais na chamada cultura popular, na própria iniciativa da população e secundariza de algum modo a importância da escola. Em contrapartida, a Pedagogia Histórico-Crítica valoriza a escola como um instrumento de acesso ao saber sistematizado, ao conhecimento científico. No caso da pedagogia de Paulo Freire esse aspecto é menos enfatizado, ocupando um lugar mais secundário. $E$, por consequência disso, também a metodologia $e$ respectivos procedimentos se diferenciam (CAMARGO; CASTANHA, 2016, p.6).

No início da década de 2000, as pedagogias críticas contra-hegemônicas, na rede municipal de Francisco Beltrão, sofreram uma grande ruptura motivada pelas políticas neoliberais nacionais e estaduais em que o Brasil era governado por Fernando Henrique Cardoso, e o Paraná, por Jaime Lerner. Nesse contexto, no ano de 2001, na primeira gestão do prefeito Vilmar Cordasso-PP (2001-2004), foi construída uma proposta fundamentada na teoria construtivista, nos PCN's e com projetos voltados para a pedagogia empreendedora.

O principal expoente do construtivismo foi Jean Piaget, que embasou a teoria do "aprender a aprender", pela qual, o importante é que o indivíduo seja capaz de absorver o maior número de informações dentro ou fora da escola, de modo que o conhecimento seja construído pelo sujeito mediante trocas de experiências, entre si, por um processo de adaptação. A ideologia da pedagogia do aprender a aprender é muito significativa no contexto neoliberal e pós-moderno, no qual se nega o papel da escola e do conhecimento universal. Segundo essa concepção, estamos submetidos a constantes mudanças, podendo aprender em todos os espaços e mediante quaisquer circunstâncias, e isso faz com que a escola se torne uma instância flexível e mutável acompanhando o ritmo e as necessidades produtivas do capitalismo.

O construtivismo parte do princípio de que o ser humano é dotado de potencialidades naturais e diferentes, o que reforça os ideários meritocráticos e acentua o individualismo e a competitividade, favorecendo o desenvolvimento dos mecanismos de exclusão entre as classes. Nessa perspectiva, Marsiglia aponta que:

Os sujeitos são preparados para serem flexíveis e adaptáveis às necessidades do mercado; tornando-os dóceis aos desígnios do capitalismo, a exploração do homem pelo homem é naturalizada e a classe dominante isenta-se da responsabilidade de oferecer condições ao desenvolvimento máximo de todos os indivíduos (2011, p. 17). 
Guiados por esses princípios neoliberais e da livre iniciativa, em que a criança deve ser levada a descobrir e criar suas próprias verdades em relação ao mundo, foi implantado no município de Francisco Beltrão e região, entre os anos de 2003 e 2005, o projeto da Pedagogia Empreendedora, que tem como principal expoente Fernando Dolabela, o qual definiu sua proposta como:

\begin{abstract}
A pedagogia empreendedora é uma estratégia didática para o desenvolvimento da capacidade empreendedora dos alunos da educação infantil até o nível médio, que utiliza a teoria empreendedora dos sonhos (...) em um primeiro momento, o aluno desenvolve um sonho, um futuro onde se deseja chegar. Em segundo momento, ele busca realizar o sonho e para isso se vê motivado a aprender o necessário para esse objetivo. $O$ objeto da pedagogia empreendedora é estimular e preparar o aluno para sonhar e buscar a realização do sonho. (...) A necessidade de conhecimento nasce da vontade inelutável de ter acesso aos elementos necessários a realização do sonho. As atividades de buscar, aprender com os erros, e, portanto, evoluir dizem respeito ao saber empreendedor. Assim, a atividade pedagógica vai se dedicar principalmente a conexão entre o sonho e sua realização (2003, p. 55).
\end{abstract}

Essa pedagogia procurava extinguir aulas expositivas e utilizava métodos, como: filmes, jogos, peças teatrais, depoimentos e entrevistas com lideranças da comunidade, para mostrar como é possível alcançar os sonhos e ser bem-sucedido.

Os professores que trabalharam na execução desse projeto afirmam que a prefeitura fornecia apostilas com aulas prontas, e eram desenvolvidas atividades de valorização pessoal, desenvolvimento de lideranças e autoconhecimento, fazendo com que os alunos descobrissem os caminhos para realização de seus sonhos. Conforme relatos, eram feitos também passeios em empresas, palestras com empreendedores para socializar as suas experiências, além de outras atividades prazerosas e que desenvolvessem as suas aptidões individuais.

Observamos que esse projeto representou um grande distanciamento em relação à PHC, pois nega totalmente o ensino dos conteúdos clássicos e desloca a função da escola para o ensino de "como sonhar". Assim, os sonhos passam a ser princípio e o fim do aprendizado, deixando de lado a problematização e mudança da prática social. O problema de cada um é realizar seu sonho.

A aprovação do Plano Nacional de Educação, em 2001, causou mudanças na organização da educação municipal. Esse documento tinha como uma de suas metas promover a universalização do ensino para a população na faixa etária de 7 a 14 anos. De acordo com esse pressuposto, em 2006 foi implementada a lei 11.274 que ampliou o ensino fundamental para nove anos, firmado nos seguintes objetivos: 
a) Melhorar as condições de equidade e de qualidade da Educação Básica;

b) Estruturar um novo ensino fundamental para que as crianças prossigam nos estudos alcançando maior nível de escolaridade;

c) Assegurar que ingressando mais cedo no sistema de ensino, as crianças tenham um tempo mais longo para aprendizagem da alfabetização e do letramento (BRASIL, 2007, p. 5).

Com a implementação do Ensino fundamental de nove anos, veio à tona a discussão sobre a criança, enquanto sujeito histórico-social que produz e é produzido pela cultura. Conforme podemos pontuar nas orientações do MEC para inclusão das crianças de 6 anos no ensino fundamental:

Crianças são sujeitos sociais e históricos, marcadas, portanto, pelas contradições das sociedades em que estão inseridas. A criança não se resume a ser alguém que não é, mas que se tornará (adulto, no dia em que deixar de ser criança). Reconhecemos o que é específico da infância: seu poder de imaginação, a fantasia, a criação, a brincadeira entendida como experiência de cultura. Crianças são cidadãs, pessoas detentoras de direitos, que produzem cultura e são nela produzidas (BRASIL, 2007 p.15).

Devido a essas mudanças na organização dos níveis de ensino, no ano de 2007, em conformidade com a deliberação estadual $n^{\circ} 03 / 06$, que normatizou a ampliação do Ensino Fundamental para nove anos no Paraná, a Rede Municipal alterou os seus Projetos PolíticoPedagógicos e as Propostas Curriculares das escolas.

Naquele contexto, o Paraná era novamente governado por Requião (2003-2010), que pautou sua política educacional alicerçada em alguns dos pilares da PHC. Considerando esses determinantes, o município de Francisco Beltrão-PR, no segundo mandato do prefeito Vilmar Cordasso-PP (2005-2008), com o propósito de alinhar as teorias educacionais com o Estado, também buscou implantar essa pedagogia na sua proposta pedagógica. Conforme indicou em entrevista, Célio Steimbach, diretor pedagógico da secretaria municipal de educação na época:

Foi no governo Requião, que foi discutido a histórico-crítica, isso fez com que gente no município, que é subordinado a legislação estadual, também entrasse na histórico-crítica. Até para acompanhar, pro município não ter uma pedagogia diferente, visto que os alunos continuariam na rede estadual, seria interessante que a gente tivesse a mesma pedagogia (STEIMBACH, 2015).

Ao analisarmos as propostas pedagógicas formuladas em 2007, observamos que estavam fundamentadas, teoricamente, na Pedagogia Histórico-Critica, representando uma crítica radical com relação à concepção de educação que se tinha até então. O Plano Municipal de Educação aprovado também naquele ano, definiu as propostas pedagógicas como "fio condutor do trabalho pedagógico. Nela estão contempladas metas e objetivos

$\begin{array}{llllll}\text { (C) ETD-Educação Temática Digital } & \text { Campinas, SP } & \text { v.20 } & \text { n.1 } & \text { p. } 98-117 & \text { jan./mar.2018 }\end{array}$


que norteiam as atividades, desenvolvidas na unidade escolar" (FRANCISCO BELTRÃO, 2007, p. 66) ${ }^{6}$ e, portanto, todo o trabalho docente. Assim, os documentos apresentam uma concepção teórica de homem, educação, e sociedade coerente com os pressupostos de uma educação emancipatória.

No entanto, observamos que inúmeros projetos extraclasses adentram em nossas escolas e acabam atrapalhando a execução dessa pedagogia, esvaziando os currículos dos saberes clássicos. O plano municipal de educação e os projetos político-pedagógicos indicam que as escolas desenvolvem atividades voltadas para o meio ambiente, educação para o trânsito, educação fiscal, prevenção de drogas entre outros. Diante de toda essa sobrecarga de atividades, causada por conteúdos oriundos de projetos externos, que chegam até a escola, percebemos que os professores acabam se prendendo na rotina pedagógica e passam a não terem tempo e condições para planejarem suas aulas, de modo coerente com os objetivos da pedagogia emancipatória, propostos pela PHC. O desenvolvimento dessa prática também implica a redistribuição dos tempos escolares, visto que não se consegue prever, precisamente, quanto tempo os alunos levarão para modificarem suas consciências com relação a determinados conteúdos, isso pode demorar muito mais que uma aula.

Além desse desafio, temos o sistema avaliativo que está a serviço de medir os índices de aprendizagem, que servem aos interesses capitalistas, o que vai, portanto, na contramão da PHC. Alguns conteúdos são priorizados como forma de garantir o sucesso dos alunos nas avaliações, em detrimento de outros necessários para promover a liberdade humana.

Na rede Municipal de Educação de Francisco Beltrão, a Escola Municipal XV de Outubro é a que tem tentado de forma efetiva, via alguns projetos, praticar os pressupostos da PHC. A escola atende aproximadamente 280 alunos, filhos da classe trabalhadora, cujos pais são trabalhadores no comércio, indústrias ou serviços autônomos, e alguns se encontram desempregados.

Ao analisar a proposta de trabalho da escola, notamos que a prática pedagógica é organizada em torno de um conteúdo estruturante presente no cotidiano infantil, facilitando a internalização e o aprendizado dos assuntos tratados na sala de aula. Conforme indicado no seu Projeto Político-Pedagógico, a instituição procura trabalhar de forma coerente com a opção teórica adotada.

\footnotetext{
${ }^{6}$ A lei que aprovou o Plano Nacional de Educação de 2001 não obrigou os municípios a aprovarem seus planos imediatamente. Com isso, o município de Francisco Beltrão aprovou o seu plano somente em 2007, tendo validade até 2017. Já a lei que aprovou o Plano Nacional de 2014 estabeleceu o prazo de um ano para estados e municípios aprovarem seus planos. O município de Francisco Beltrão aprovou um novo plano em 2015, com validade até 2014 .
}

(C) ETD-Educação Temática Digital Campinas, SP $\quad$ v.20 $\quad$ n.1 $\quad$ p. $98-117 \quad$ jan./mar.2018


Seguimos uma tendência Histórica-Crítica, pois entendemos que a atuação da escola consiste na preparação do aluno, também para o mundo adulto e suas contradições fornecendo-lhe instrumental por meio da aquisição de conteúdos e da socialização, para uma participação organizada e ativa na democratização da sociedade (FRANCISCO BELTRÃO, PPP - ESCOLA MUNICIPAL XV DE OUTUBRO, 2007, p. 14).

Dessa maneira, a escola desenvolve alguns projetos voltados para essa perspectiva, tratando dos conteúdos de forma contextualizada e vinculados com a vivência cotidiana do aluno, com pleno significado para ele.

A prática realizada na escola consiste numa tentativa de objetivação da PHC, ainda que com alguns pontos a serem aperfeiçoados para que possamos afirmar que houve/há, de fato, a objetivação dessa teoria na Rede Municipal de Francisco Beltrão-PR. Os profissionais que desempenham o trabalho na instituição, apesar de demonstrarem compreensão dos princípios da PHC, ainda que de forma fragilizada, apontam algumas dificuldades para desenvolvê-la, tais como: deficiência nos processos de formação continuada oferecidos pela Secretaria Municipal, com relação à temática; pouca disponibilidade de material para estudo; sobrecarga de conteúdos presente na proposta curricular, tanto que esses projetos são desenvolvidos somente com alunos do 1 을 ao 3 o ano, do 10 ciclo. Os professores enfatizam que as séries superiores têm uma maior demanda de assuntos para serem trabalhados, tornando inviável a perspectiva da PHC, pois essa metodologia é mais demorada que as outras. Ainda os educadores relatam sentirem dificuldades em fazer a transposição didática do saber popular para o erudito, pois isso demanda um preparo do professor, o que implica um tempo maior de planejamento.

\section{CONSIDERAÇÕES FINAIS}

A Pedagogia Histórico-Critica, sustentada teoricamente por pensadores marxistas, visa a instrumentalizar a classe trabalhadora para atingir sua emancipação, possibilitando uma transformação social, pela qual, as diferenças entre as classes sejam suprimidas. Saviani, embasado em autores como Marx, Lênin e Gramsci formulou essa teoria pedagógica, de natureza revolucionária, que tem por princípio formar seres humanos livres das armadilhas capitalistas.

Ela ganhou força no Brasil na década de 1980, com o processo de abertura democrática, um momento que favoreceu o desenvolvimento de pedagogias voltadas aos interesses dos trabalhadores, em contraposição às concepções pedagógicas em uso até então. No mesmo contexto de redemocratização, ela também começou a ser discutida no Estado do Paraná e foi instituída em 1990 com a implantação do Currículo Básico que, embora apresentasse contradições teóricas-metodológicas, carregava os principais princípios da PHC.

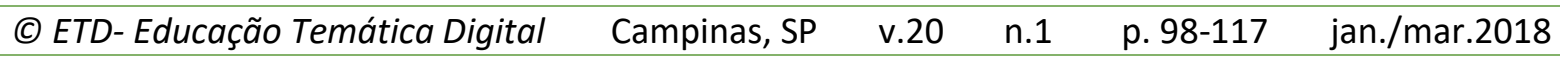


Entendemos que a PHC, por ser de natureza revolucionária, defende interesses antagônicos ao que preconiza o Estado capitalista e liberal. Assim, sua verdadeira implantação não depende somente de um discurso político-ideológico, mas, sim, requer uma organização de luta e enfrentamento, a partir de uma concepção teórica clara por parte daqueles que realmente fazem a educação acontecer. Cabe, portanto, salientar que a PHC não deve ficar restrita somente aos meios didáticos, visto que ela não é meramente uma metodologia, mas uma teoria pedagógica transformadora que expressa uma ideologia e uma visão política e, portanto, reduzi-la a seus princípios didáticos é um dos empecilhos para sua objetivação.

Embora as propostas pedagógicas curriculares do Paraná e de Francisco Beltrão estejam fundamentadas pela PHC, o que de certo modo é um avanço (pois seria mais complicado lutar contra a política educacional), sua efetivação ainda permanece um tanto quanto utópica, pois a forma como as escolas estão organizadas não condiz com os pressupostos dessa pedagogia, por isso, ela acaba permanecendo, muitas vezes, apenas nas formulações teóricas dos documentos.

Entendemos que, somente a partir de uma formação sólida, é que os docentes terão condições de elaborar um planejamento e um currículo coerente com os princípios da PHC; buscar melhores condições de trabalho; posicionar-se em defesa da escola pública; primando pela qualidade da educação, mediante a socialização das bases científicas e com condições de desenvolverem uma visão politizada sobre a educação.

Ao analisar os caminhos da Pedagogia Histórico-Crítica em Francisco Beltrão, ficou evidente que se tem muito a caminhar para que a PHC passe de um objetivo proclamado nos documentos e se torne prática real. Ficou evidente que precisamos agir a partir de condições concretas, tendo claro que a história se constrói mediada por ações humanas conscientes e coletivas e que, por isso, é plenamente possível realizar uma outra educação, voltada para a emancipação da classe trabalhadora.

\section{'REFERÊNCIAS BIBLIOGRÁFICAS}

BACZINSKI, A. V. M. A implantação oficial da pedagogia histórico-crítica na rede pública do estado do Paraná (1983-1994): legitimação, resistências e contradições. Campinas, São Paulo: Autores Associados, 2011. Coleção memória da educação.

BRASIL. Ministério da Educação. Secretaria de Educação Fundamental. Ensino fundamental de nove anos: orientações para a inclusão da criança de 6 anos de idade. Brasília, DF, 2007.

BRASIL. Lei $\mathrm{N}^{\circ} 11.274$, de 06 de fevereiro de 2006. Altera a redação dos arts. 29, 30, 32 e 87 da Lei no 9.394, de 20 de dezembro de 1996, que estabelece as diretrizes e bases da educação nacional, dispondo sobre a duração de 9 (nove) anos para o ensino fundamental,

$\begin{array}{llllll}\text { (C) ETD-Educação Temática Digital } & \text { Campinas, SP } & \text { v.20 } & \text { n.1 } & \text { p. } 98-117 & \text { jan./mar.2018 }\end{array}$


com matrícula obrigatória a partir dos 6 (seis) anos de idade. Diário Oficial da União, Brasília, 07 fevereiro 2006. Disponível in: http://www.planalto.gov.br/ccivil 03/ Ato20042006/2006/Lei//11274.htm _Acesso em: 05 de maio de 2017

CAMARGO, T. L. de e CASTANHA, A. P. Os pressupostos teóricos metodológicos da Pedagogia Histórico-Crítica e os desafios da sala de aula: entrevista com Dermeval Saviani. Educere et Educare, v. 11, n. 22, jul./dez. 2016. Publicação Ahead of Print.

DOLABELA, F. Pedagogia empreendedora. São Paulo: Editora de Cultura, 2003.

FAVARO, N. Pedagogia histórico-crítica e sua estratégia política: fundamentos e limites. Florianópolis: Em Debate/UFSC, 2015. E-book. Disponível em: https://issuu.com/editoriaemdebate/docs/pedagogia-historico-critica1 Acesso em: $10 \mathrm{de}$ maio de 2017.

FRANCISCO BELTRÃO. Secretaria Municipal de Educação. PROPOSTA PEDAGÓGICA CURRICULAR CRIANÇA CIDADÃ. Francisco Beltrão, PR, 1998.

FRANCISCO BELTRÃO. Plano Municipal de Educação (2007-2017). Francisco Beltrão: Grafisul, 2007.

FRANCISCO BELTRÃO. Secretaria Municipal de Educação. Projeto Político-Pedagógico, Escola Municipal XV de Outubro. Francisco Beltrão, PR, 2007.

FRIGOTTO, G. Os circuitos da história e o balanço da educação no Brasil na primeira década do século XXI. Revista Brasileira de Educação. 2011, vol. 16, n. 46, p. 235-254.

LAZARINI, A. Q. A relação entre capital e educação escolar na obra de Dermeval Saviani: apontamentos críticos. $528 \mathrm{f}$. Tese (Doutorado em Educação). Universidade Federal de Santa Catarina, Centro de Ciências da Educação, Programa de Pós-Graduação em Educação. Florianópolis, 2010.

MAGALHÃES, C. H. F. Obstáculos da Pedagogia Histórico-Crítica no cotidiano da escola. Maringá: EDUEM, 2012.

MARSIGLIA, A. C. G. A prática pedagógica histórico-crítica na educação infantil e ensino fundamental. Campinas: Autores Associados, 2011.

MARX, K. e ENGELS, F. Textos sobre educação e ensino. Tradução de Ruben Eduardo Frias. 4.ed. São Paulo: Centauro, 2004.

MORGAN, N. L. Entrevista concedida para Tassia Lima de Camargo em 08 de março de 2015. ORSO, P. J. e TONIDANDEL, S. A pedagogia histórico-crítica e o currículo básico para a escola pública do Paraná - 1990: do mito à realidade. In: ORSO, P. J. e outros (Orgs). Pedagogia Histórico-Crítica e a Educação Brasileira e os desafios de sua institucionalização. CuritibaPR: CRV, 2014, p. 125-140.

$\begin{array}{llllll}\text { (C) ETD- Educação Temática Digital } & \text { Campinas, SP } & \text { v.20 } & \text { n.1 } & \text { p. } 98-117 & \text { jan./mar.2018 }\end{array}$


PARANÁ. Currículo básico para a escola pública do estado do Paraná. Secretaria de Estado da Educação do Paraná. Curitiba, PR. SEED,1990.

PARANÁ. Conselho Estadual de Educação. Deliberação n. 03/06, de 09 de junho de 2006. Normas para a implantação do Ensino Fundamental de 9 (nove) anos de duração no Sistema Estadual de Ensino do Estado do Paraná. Disponível em:

http://www.cee.pr.gov.br/arquivos/File/pdf/Deliberacoes/2006/Deliberacao 03 06.pdf Acesso em: 15 de fev. 2016.

PITON, I. M. Políticas educacionais e Movimento sindical docente: reformas educativas e conflitos docentes na educação básica paranaense. 293 f. Tese (Doutorado em Educação). Universidade Estadual de Campinas, Faculdade de Educação. Campinas, 2004.

ROSA, R. da; e CASTANHA, A. P. A presença da Pedagogia Histórico-Crítica nas escolas públicas da rede estadual de Francisco Beltrão - PR. In: SEMINÁRIO NACIONAL DE PESQUISA EM EDUCAÇÃO: CONEXÕES E DIÁLOGOS NA PÓS-GRADUAÇÃO, 1, 2015, Francisco Beltrão. Anais ... Francisco Beltrão: Unioeste, 2015. v.1. p.1-17.

SAVIANI, D. Aberturas para a história da educação: do debate teórico-metodológico no campo da história ao debate sobre a construção do sistema nacional de educação no Brasil. Campinas-SP: Autores Associados, 2013

SAVIANI, D. Escola e democracia. 40. ed. Campinas, SP: Autores Associados, 2008.

STEIMBACH, C. J. Entrevista concedida para Tassia Lima de Camargo em 24 de abril de 2015.

TONIDANDEL, S. Pedagogia Histórico-Crítica: o processo de construção e o perfil do "Currículo Básico para a Escola Pública do Estado do Paraná" (1980-1994). 223 f.

Dissertação. (Mestrado em Educação). Universidade Estadual do Estado do Paraná, Centro de Educação Comunicação e Artes, Programa de Pós-Graduação em Educação. Cascavel-PR, 2014.

TUMOLO, Paulo Sergio. O trabalho na forma social do capital e o trabalho como princípio educativo: uma articulação possível? Educação e Sociedade, Campinas, vol. 26, n. 90, jan/abr., 2015, p. 239-265.

TUMOLO, Paulo Sergio. Trabalho, educação e perspectiva histórica da classe trabalhadora: continuando o debate. Revista Brasileira de Educação. v. 16. n. 47, maio-ago, 2011, p. 443481.

\footnotetext{
' Revisão gramatical do texto sob a responsabilidade de: Profa. Dra. Benedita de Almeida.
}

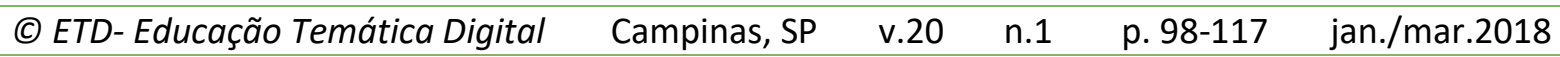

